\title{
Interoperability and Learning Objects: An Overview of E-Learning Standardization
}

\author{
Norm Friesen, CanCore Initiative \\ Athabasca University, Athabasca, Canada
}

normf@athabascau.ca

\begin{abstract}
The observation "the nice thing about standards is that there are so many to choose from" (Tanenbaum, 1981, p. 221) has been circulating in e-learning standards circles for some time. This statement certainly reflects the varied and complex nature of standards organizations and standards development processes. This paper provides an overview of standards and specifications bodies and processes relevant to e-learning and particularly to learning objects and related infrastructures. It focuses specifically on three key organizations and on the e-learning specifications and the standards they develop: the IMS Global Consortium, the IEEE LTSC (Institute of Electrical and Electronics Engineers, Inc. Learning Technology Standards Committee), and the ISO/IEC (International Standards Organization/International Electrotechnical Commission).
\end{abstract}

Keywords: standards, specifications, learning object metadata, ISO, IEEE, learning design

\section{Introduction}

Standards can be defined as "documented agreements containing technical specifications or other precise criteria to be used consistently as rules, guidelines, or definitions of characteristics, to ensure that materials, products, processes and services are fit for their purpose" (Bryden, 2003;

p. 3). In the context of e-learning technology, standards are generally developed to be used in systems design and implementation for the purposes of ensuring interoperability, portability and reusability. These attributes should apply to both the systems themselves and of the content and metadata they manage.

Standards and standardization processes are important to adopters and ultimately to end users, but not always for the reasons given by advocates and promoters. Typical of supporting arguments are claims that e-learning standards "will produce better learning, education, and training - which [will have] a positive effect upon all societies" (ISO 2002, p. 3). This positive potential or hopeful outcome of standardization is certainly reason enough for technology users and standards adopters to be aware of general developments in e-learning standardization. However, it is the ambiva-

Material published as part of this journal, either on-line or in print, is copyrighted by the publisher of the Interdisciplinary Journal of Knowledge and Learning Objects. Permission to make digital or paper copy of part or all of these works for personal or classroom use is granted without fee provided that the copies are not made or distributed for profit or commercial advantage AND that copies 1) bear this notice in full and 2) give the full citation on the first page. It is permissible to abstract these works so long as credit is given. To copy in all other cases or to republish or to post on a server or to redistribute to lists requires specific permission and payment of a fee. Contact Publisher@ijklo.org to request redistribution permission. lent, complex and uncertain effects of technical standards on processes and products that are much less often remarked upon, and that can be of equal if not greater importance to adopters and ultimately, end users (e.g. Slaton \& Abbate, 2001). Both perspectives on standardization are represented below. In this sense, this article hopes to communicate as much a caveat emptor as a carpe diem to readers at this juncture in the ongoing develop- 
ment of e-learning standardization.

An important part of the standardization process is the development of "specifications." Specifications can be said to represent standards early in their development, prior to receiving approval from standards bodies, and they tend to be experimental, incomplete and more rapidly evolving (Farance, 1999). They capture a rough consensus, and are meant to enable technology development and the management of short-term risk. Standards, on the other hand, are much more conclusive, complete, and evolve much more slowly. They should capture general acceptance, can serve regulatory purposes, and be used to manage long-term risk (Farance, 1999).

In e-learning, both standards and specifications are often multi-part, typically consisting of:

1) a "data model" which specifies the standard's "normative" content in abstraction,

2) one or more "bindings," which specify how the data model is expressed in a formal idiom, which is most often XML, and

3) an "API" (Application Programming Interface) or "service definition" that is somewhat less often provided to define points of contact between cooperating systems (see, for example: IEEE, 2004).

The development of technical standards and specifications in e-learning can be seen as part of the maturation of this recently emergent field or industry. According to a recent survey of the Information Technology (IT) industry in The Economist, similar process of industry maturation has occurred in a wide variety of sectors:

railways, electricity, cars and telecommunications all learned to love standards as they came of age. At a certain point in their history, it became clear that rather than just fighting to get the largest piece of the pie, the companies within a sector needed to work together to make the pie bigger. Today, the IT industry is finally getting the standards religion. ("Survey," 2003, p. 14)

"Getting the standards religion" can also be said to characterize what has been happening in the elearning sector as well. Since the advent of the personal computer, digital technologies have of course become increasingly common in education --both in distance and classroom education and training settings. However, these technologies have typically been applied in ad hoc and divergent forms: Innumerable courses, course components and systems for managing and delivering them have been developed independently of one another, often at great expense. Moreover, this content and these systems are often created in a manner that makes it very difficult, if not impossible, to support their interchange or their successful interoperation. Standards and specifications in e-learning address these shortcomings by ensuring the interoperability, portability and reusability of this content and of these systems.

Because of their increasing importance over the last century technical and industrial development, standards have recently been receiving significant attention from historians and other scholars of technology. Many of the themes and lessons identified in historical and theoretical studies of standards and their significance apply to e-learning standardization as well. Both in general and in e-learning in particular, standards can be understood as "instruments that encode and order labor relations" (Slaton \& Abbate, 2001) --whether this labor is physical or intellectual in character: "the adoption of standards may simplify some aspects of [a] system while creating a demand for more skilled labor elsewhere" (Slaton \& Abbate, 2001). Librarians and indexers who have worked, for example, on the implementation of the Dublin Core or IEEE Learning Object metadata standards, will likely have first-hand knowledge of the labor-intensive requirements and challenges that these standards can introduce. Far from being "pedagogically neutral" (see Friesen, 2004a) or serving merely as "instruments [for the] reduction" of complexity or costs 
(Slaton \& Abbate, 2001), standards can redefine or reinforce existing relations or processes -often in ways that are difficult to foresee: "The end is not always predicable: some standards build in flexibility to accommodate local conditions; other fail when confronted with resistant users." This significant unpredictability and uncertainty applies just as surely to manufacturers of machine parts or developers of Internet protocols (Abbate, 1999) as it does to the adoption of elearning object models and metadata.

\section{Alphabet Soup: IMS, LTSC, and ISO/IEC JTC1 SC36}

This document begins with an overview of the major organizations mentioned above that contribute to the development of e-learning standards --the IMS, IEEE LTSC, and the ISO/IEC. There are, of course, other standards organizations (many of them national standards bodies) that may make significant contributions to international e-learning standards development, but which fall outside of the scope of this article. These include ANSI (American National Standards Institute), NISO (National Information Standards Organization), DIN (Deutsches Institut für Normung), BSI (British Standards Institute), and the CSA (Canadian Standards Association).

\section{IMS}

The IMS Global Learning Consortium, Inc. (IMS) "develop[s] and promote[s] open specifications for facilitating online distributed learning activities" (IMS, 2003). The IMS is a consortium formed by almost 200 commercial, governmental and other entities. Currently, the IMS has some 80 contributing members, a significant number of which are American and British commercial entities, but which also include universities and federal governmental agencies. The membership is largely English-speaking, which sometimes leads to a de-emphasis on multilingual and multicultural concerns. At the same time, the IMS is the only standards development organization highlighted here that has significant, direct representation from those involved in the school or K-12 sector. This representation includes governmental representation from education ministries, as well as SIF (Schools Interoperability Framework), and OKI (the Open Knowledge Initiative). Moreover, the number of nationalities and sectors represented by this membership has recently been expanding. The IMS is very attentive to the needs of those in the educational community generally, and has the highest recognizability within this community of the standards development organizations considered here. Contributing members must pay a \$50,000 annual fee, and are able to vote on the IMS technical board for the acceptance, rejection or revision of specification drafts. Plenary-style meetings are held quarterly, often in North American locations, and individual working group meetings are held separately and also in conjunction with quarterly meetings.

\section{IEEE LTSC}

The IEEE "is a non-profit, technical professional association of more than 380,000 individual members in 150 countries" (IEEE, 2002). It is also an accredited standards development organization. Within the IEEE, the LTSC focuses on standards development specifically in the area of elearning technologies --producing "accredited technical standards, recommended practices and guides" (LTSC, 2002). The LTSC also "coordinates formally and informally with other organizations that produce specifications and standards for similar purposes" (LTSC, 2002). These other organizations include the IMS and the e-learning standards development body in the ISO/IEC. Memberships to the LTSC are granted to individuals, regardless of institutional affiliation or specialization at a cost of \$200 US annually per membership. The LTSC's active membership includes individuals from small and large private sector organizations, the US military and affiliated organizations, and from governmental organizations and universities of various nationalities. LTSC meetings are held bi-annually, in locations across the world. The LTSC, like the IEEE as a 
whole, is a respected source of standards, especially in the English-speaking world. However, standards are seen as benefiting significantly from the approval that can only be conferred by organizations such as the ISO and IEC --organizations with official, delegated international representation.

\section{ISO/IEC}

The ISO is an internationally and UN-recognized body for standardization founded in 1946. It is responsible for creating standards in many areas, including computers and communications. Its members comprise the national standards organizations of approximately 140 countries. The IEC is a similar international organization that "prepares and publishes international standards for all electrical, electronic and related technologies." (IEC, 2002) To avoid duplication of efforts, the ISO and IEC formed a Joint Technical Committee (JTC1) to "develop, maintain, promote and facilitate IT standards" in a number of areas of common interest (JTC1, 2002). One of the Sub Committees of JTC 1, SC36, was formed in 2000 with the task of developing standards specifically for e-learning. SC36 is also known as the Sub Committee on "Information Technology for Learning, Education, and Training." In SC36 (as is the case in JTC1, ISO and the IEC generally), participation occurs on the basis of national representation. In passing resolutions, drafts and standards documents, one vote is given to each country at the table, with each nation being represented by a nationally appointed delegation or body. At the most recent SC36 plenary, more than

one dozen national bodies were represented. Plenary meetings of SC36 are held twice annually, in conjunction with multiple meetings of SC36 working group. Of the e-learning standards development organizations described here, SC36 is unique in the explicitly international, multi-lingual character of its representation, and in its emphasis on formally coordinating standards development in e-learning with relevant standards activities in other areas. (SC36 maintains formal liaisons with a number of other subcommittees in JTC1, in ISO itself, and with other standards organizations, including the LTSC.)

\section{Red Hot to Cool Blue: The Standards Development Process}

A widely-circulated diagram that schematizes the e-learning standards development process (Figure 1) has been provided by the IMS. It can serve as a good starting point for understanding how the IMS, LTSC, and SC36 work together and with the e-learning community. This diagram depicts the standards development process as a predominantly linear one. Although this process is depicted as cycling through iterations and feedback loops, it ultimately appears to move from "research and development concepts" and "user needs" to eventually arrive at "approved standards." In the original version of this diagram, the work and activity of stakeholders and developers is shown in red, with the colour blue used to suggest the "cooled" stability of officially approved standards.

This diagram indicates how implementations, reference models, specifications and standards can be understood as fitting together into an overall "standardization" process. Implementations and reference models refer to ways that specifications and standards are applied in communities. They include systems and tool development, as well as "application profiling" work that integrates multiple specifications or standards (e.g. SCORM, the "Sharable Content Object Reference Model," (ADL, 2003)) or interprets and applies a single standard (e.g. CanCore (see Duval, Hodgins, Sutton, \& Weibel, 2002; Friesen, Hesemeier, Fisher, Roberts, \& Habkirk, 2004 for more on application profiles)). A significant proportion of implementation and profiling work mediates between the abstraction of many standards and specifications and the particularities and requirements of implementation. 


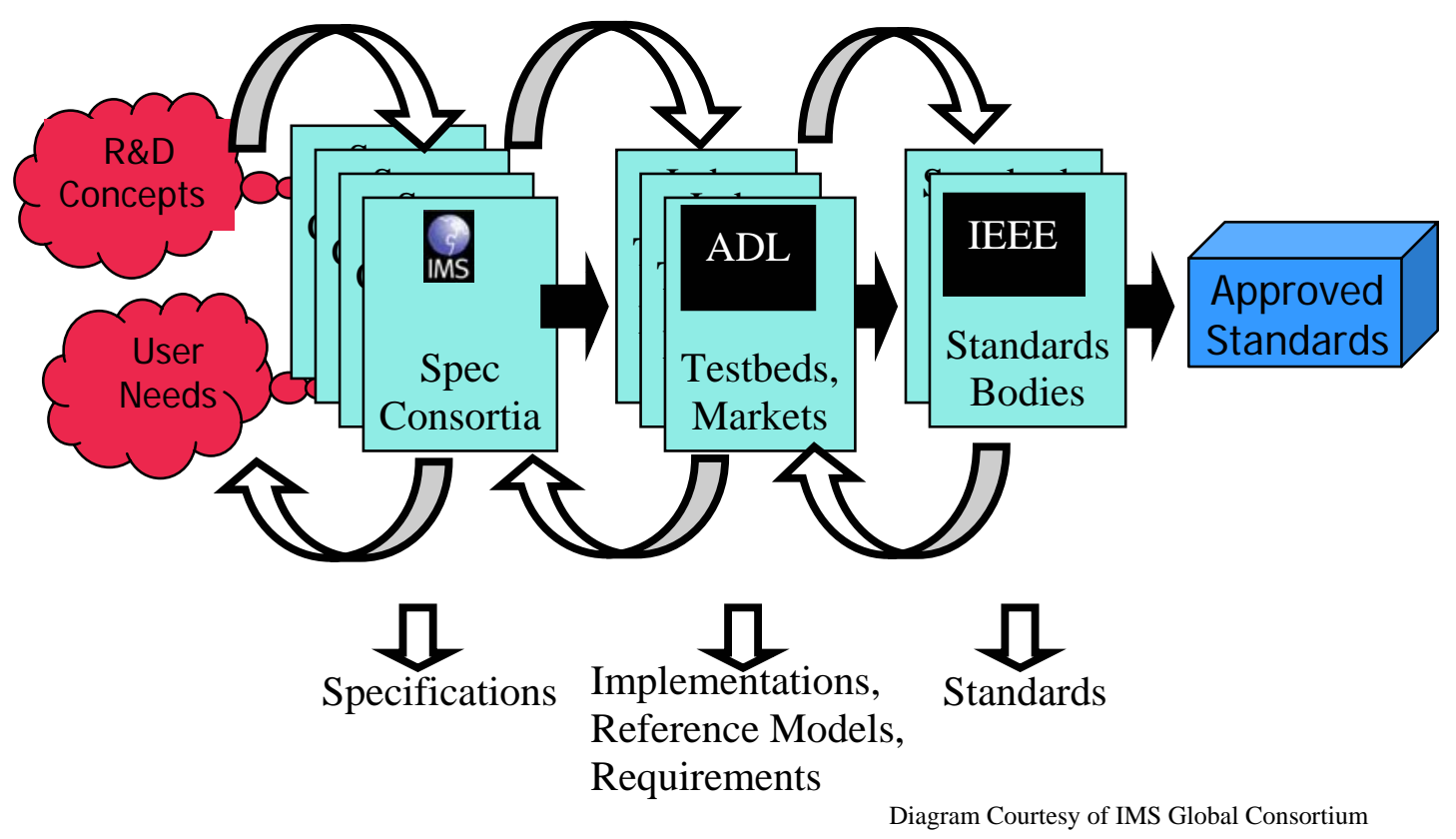

Figure 1: E-learning standards development process

The IMS diagram also makes it clear that the activity of the IMS and similar organizations only applies to the development of specifications. Other organizations that generate specifications include the AICC (Aviation Industry CBT [Computer-Based Training] Committee) and the W3C (World Wide Web Consortium). The AICC has developed nine "AICC Guidelines and Recommendations" resources --one of which is referenced in SCORM, and has been standardized by the LTSC, and is being submitted to SC36. The W3C "develops interoperable technologies (specifications, guidelines, software, and tools) to lead the Web to its full potential" (W3C, 2002). It has been responsible for developing XML and other specifications that form the foundation upon which e-learning and other standards and specifications are now being built.

The IMS diagram is slightly less accurate in indicating the way that user and stakeholder needs and input are integrated into the standards development process. These inputs often inform standards at all stages of their development --not just at the beginning. SC36, for example, has its own standards development cycle in which standards can be developed "from scratch" --based only on needs and concepts of stakeholder communities. Moreover, on its way to becoming a standard, a given specification tends not to move in linear or even circular/iterative fashion that is easy to delineate. As will be illustrated below, standardization work can be shared across the IMS, LTSC and SC36 in a manner that sometimes appears to be ad hoc, through arrangements derived from mutual need, or as a result of political considerations.

In the case of the IMS, the LTSC and SC36, standards development work is apportioned to working groups, with each working group developing a specification or standard during a period of time that can last from 9 months to 2 or more years. Because a standard or specification can develop through a number of successive generations, the lifetime of a working group will sometimes be longer rather than shorter. A second diagram from the IMS (Figure 2) schematizes this standards or specifications development process --showing very clearly how it occurred at one point in the IMS itself. 
User Needs, Technical Means, Practical Constraints

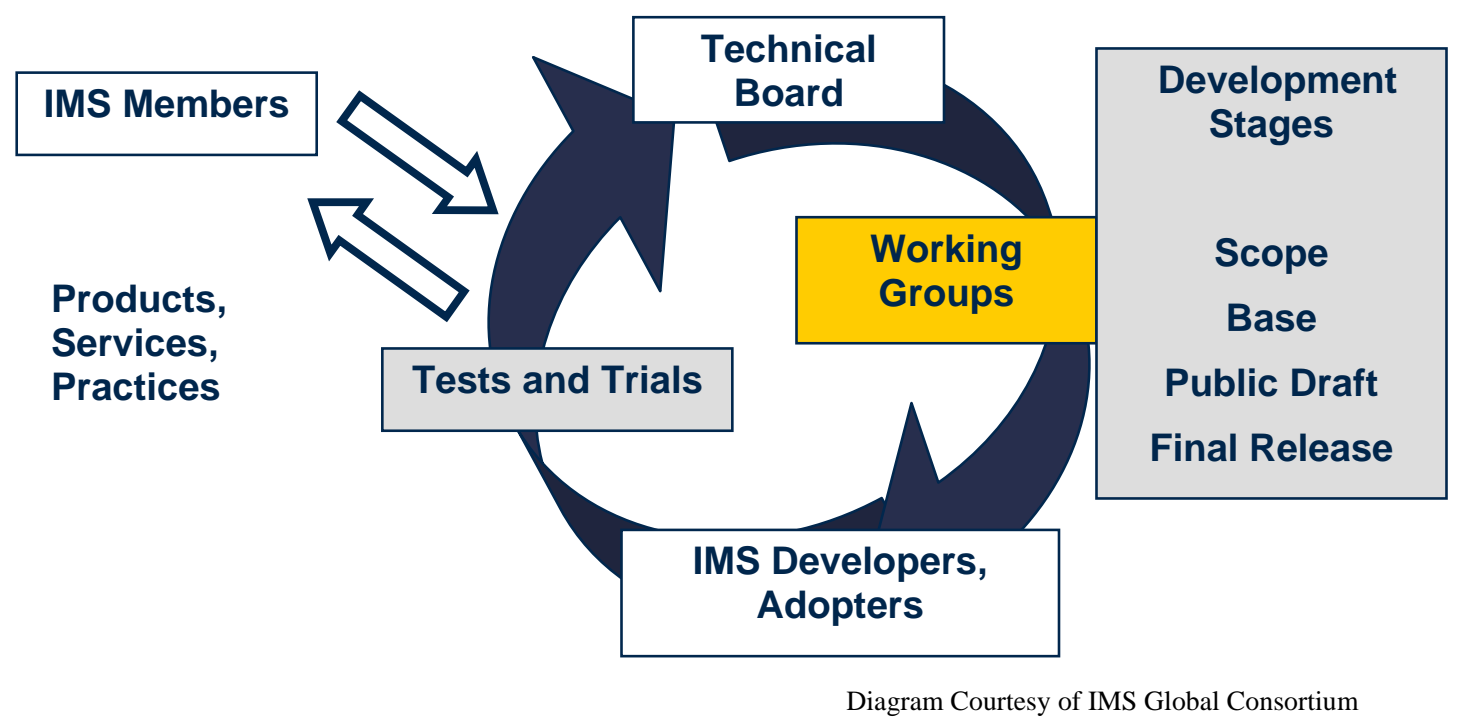

Figure 2: Standards or specifications development

In the case of each organization --IMS, LTSC and SC36-- working group activity is governed by a plenary body. Formal applications for starting new working groups or working group activity must be approved by this body. As the above diagram also shows, working group activity is expected in each organization to feed into the community of developers and implementers, whose feedback and requirements are to be incorporated into standards as they are developed. Also, each organization develops standards or specifications documents through a prescribed set of stages, beginning with a proposal or scope, and proceeding through base or committee drafts through to a stable version that is released to the public. In the case of the LTSC and ISO/IEC JTC1 SC36, documents proceed from one stage to the next through a highly formalized balloting procedure, in which numerous comments must be individually addressed.

\section{Lifecycle of a Standard}

This section briefly presents the history of two particular areas of specification activity as case studies in standards development: 1) the development of the IEEE Learning Object Metadata (LOM) standard, and 2) the IMS Learning Design specification (IMS LD). The history of these normative documents illustrates the intricate, inter-organizational dynamic of the standards development process and highlights the complex interaction of community requirements and standards development.

\section{IEEE Learning Object Metadata}

The IEEE LOM, a standard that is central to learning objects and repositories, was originally developed in response to the very practical needs of those assembling online collections of reusable learning materials that required standardized metadata for the purposes of discovery, management and resource sharing within and between collections. In 1996, the IMS (then known as the "Instructional Management Systems" consortium), and ARIADNE (Alliance of Remote Instructional Authoring and Distribution Networks for Europe) began the joint development of the Learning Object Metadata, (at approximately the same time as the emergence of the Dublin Core Metadata 
Initiative). The development of the LOM was subsequently handed over to the IEEE LTSC, where, after multiple drafts and revisions, it was developed into an official IEEE standard.

While the LOM was being developed, implementers and others required stable, publicly available versions of the specification --both of the abstract data model, and of its bindings in XML. This need was addressed by the IMS, which developed these versions or documents, and in effect "hosted" open and stable versions of the specification for the general community. Since the IEEE standardized the LOM in 2002, the IMS is officially referencing the IEEE document, rather than referring implementers to its earlier versions of metadata documents.

The next step generally envisioned for standards like the LOM is formal standardization by the ISO/IEC through SC36, with one option being to "fast-track" the standard through a high-level JTC1 committee. However, the LOM is already very widely accepted and implemented in its current form, and its further standardization in SC36 --either via SC36 balloting procedures or "fast tracking" through JTC1-- brings with it risks of significant revision or even outright rejection. Consequently, it has been agreed by many stakeholders that stabilizing and supporting the standard in its present form is currently more important that its further standardization. As a further result, the LOM will not be subjected to further incremental revisions and minor changes. Instead, a longer-term perspective is being taken, and ways are being considered for the IEEE LTSC and the SC36 subcommittee to work together in the future to develop a "next generation" or "2.0 version" of this metadata standard over a number of years. In 2004, Norm Friesen (author of this article) and Yolaine Boudra of the French National Body were nominated to act as project editors for the two parts of this "2.0 version" of the metadata standard. Contributions to this work over the past year indicate that this new standard may be much closer in orientation to the "minimalist" Dublin Core approach to metadata (see Friesen, 2004b; Canadian National Body, 2003) than to the technically demanding, "structuralist" approach represented by the LOM.

\section{IMS Learning Design}

IMS LD is a specification that has a much shorter history than the LOM. However, the IMS LD has been the subject of great interest in a variety of e-learning research communities. This specification has its beginnings in the Open University of the Netherlands, in the form of an "Educational Modeling Language" developed by Rob Koper. This modeling language was brought -more or less mid-stream-- into an IMS working group that was originally charged with the task of developing a specification related to instructional design. This working group subsequently undertook the task of simplifying this modeling language or system, and adapting it to existing IMS specifications, including the IMS version of "Learning Object Metadata." IMS Learning Design was released as a "Version 1.0" IMS specification in February 2003, and its subsequent uptake and implementation has involved a wide variety of international initiatives or groups, as well as some systems vendors. These include the Valkenberg group the European-based "UNFOLD" community, as well as Blackboard, elive Learning Design, and LAMS (Learning Activity Management System) International.

\section{Conclusion}

Despite the permanence, stability and univocality implied by the term "standard," it is relatively clear that the processes and histories of their development are anything but predicable, unambiguous and simple. Perhaps especially in an emerging field like e-learning, standards development involves the difficult task of hitting a moving target from a position that is itself changing. The first of these is represented by emerging and accepted technological capabilities and configurations, and the second, by the standards development dynamic itself. Paradoxically, this situation makes the existence of relatively stable and readily applicable standards for e-learning all the more important. This situation also underscores the value of research that would help demystify 
the complex processes of e-learning standards development, and (perhaps more importantly) consider the possible and actual effects of these standards on common educational organization and practice.

\section{References}

Abbate, J. (1999). Inventing the Internet. Cambridge, MA: MIT Press.

ADL. (2003). Advanced Distributed Learning: SCORM Overview. Retrieved January 13, 2005, from http://www.adlnet.org/index.cfm?fuseaction=scormabt

Bryden, A. (2003) Open and Global Standards for Achieving an Inclusive Information Society. Retrieved January 13, 2005 from http://www.iso.org/iso/en/commcentre/presentations/secgen/2003/ajb2003SISTspeech.pdf

Canada National Body. (2003). [Draft] Canadian Proposal for the Multi-Part Standard for "Metadata for Learning Resources" (MLR). Retrieved December 4, 2004, from http://mdlet.jtc1sc36.org/doc/SC36_WG4_N0045.pdf

Duval, E., Hodgins, W., Sutton, S., \& Weibel, S. L. (2002). Metadata Principles and Practicalities. D-Lib Magazine, 8 (4). Retrieved December 4, 2004, from http://www.dlib.org/dlib/april02/weibel/04weibel.html

Farance, F. (1999). Learning Technology Standards Committee Work Program and Process. Retrieved December 4, 2004, from: http://ltsc.ieee.org/meeting/199912/ doc/ltsc_wg--199912--farance.ppt

Friesen, N. (2004a). CanCore: Interoperability for Learning Object Metadata. In D. Hillman \& E. L. Westbrooks (Eds.), Metadata in Practice (pp. 104-116). Chicago: ALA Editions.

Friesen, N. (2004b). Learning Objects and Standards: Pedagogical Neutrality and Engagement. Proceedings of the IEEE International Conference on Advanced Learning Technologies. Joensuu, Finland. August 30, 2004. pp. 1070-1071.

Friesen, N., Hesemeier, S., Fisher, S., Roberts, A., \& Habkirk, S. (2004). CanCore: Best Practice for Learning Object Metadata. In R. McGreal (Ed.), Learning Objects and Metadata. London: Kogan Page.

IEC (2002). IEC Website. URL http://www.iec.ch/

IEEE (2002). IEEE Website. Retrieved December 4, 2004, from http://www.ieee.org

IEEE (2004). WG11: Computing Managed Instruction. Retrieved January 13, 2005, from http://ltsc.ieee.org/wg11/

IMS (2003). IMS Website. Retrieved December 4, 2004, from http://www.imsglobal.org/

ISO (2002). Information Technology: Learning by IT. ISO Bulletin. June 2002. http://jtc1sc36.org/doc/36N0264.pdf

JTC1 (2002). JTC1 Website. Retrieved December 4, 2004, from http://www.jtc1.org/

LTSC. (2002). LTSC Website. Retrieved December 4, 2004, from http://tsc.ieee.org/

Slaton, A. \& Abbate, J. (2001) The Hidden Lives of Standards: Technical Prescriptions and the Transformation of Work in America. In M. T. Allen \& G. Hecht (Eds.), Technologies of Power (pp 95-144). Cambridge, MA: MIT Press.

Survey: The IT Industry. (2003, May 8). The Economist. Retrieved December 4, 2004, from http://www.economist.com/surveys/displaystory.cfm?story_id=1747329

Tannenbaum, A. (1981). Computer Networks (2nd ed.) New York: Prentice-Hall.

W3C. (2002). W3C Homepage. Retrieved December 4, 2004, from http://www.w3.org/ 


\section{Biography}

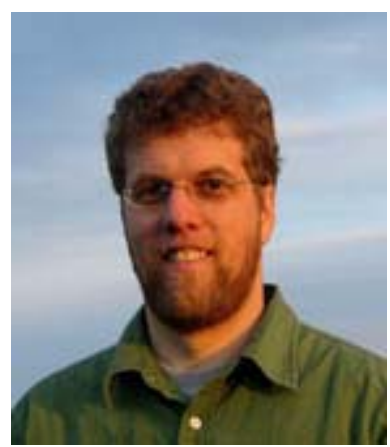

Dr. Norm Friesen has been developing and studying Web technologies in educational contexts since 1995. Norm is currently employed at Athabasca University as Director of the CanCore Learning Object Metadata Initiative, a project whose technical recommendations have been adopted internationally. Norm is also a Visiting Scholar at the School of Communication at Simon Fraser University, and is the principal investigator in the three-year "learningspaces.org" project. In addition to authoring dozens of articles and reports, Norm has produced several editions of books on the instructional use of WebCT and the implementation of the IEEE Learning Object Metadata standard. 